\title{
Impaired GH Secretion in Patients with SHOX Deficiency and Efficacy of Recombinant Human GH Therapy
}

\author{
Lorenzo lughetti $^{a}$ Silvia Vannelli ${ }^{b}$ Maria Elisabeth Street ${ }^{c}$ Piero Pirazzoli $^{d}$ \\ Silvano Bertelloni ${ }^{\mathrm{e}}$ Giorgio Radetti ${ }^{\text {h }}$ Lucia Capone $^{\mathrm{i}}$ Barbara Stasiowska ${ }^{\mathrm{b}}$ \\ Laura Mazzanti $^{d}$ Roberto Gastaldi ${ }^{f}$ Maria Cristina Maggio ${ }^{g}$ Barbara Predieri ${ }^{a}$ \\ on behalf of The Italian Society of Pediatric Endocrinology and Diabetology Study \\ Group on Growth Factors and Puberty \\ Departments of Pediatrics, Universities of ${ }^{a}$ Modena and Reggio Emilia, Modena, ${ }^{\mathrm{b}}$ Turin, Turin, 'Parma, Parma, \\ ${ }^{\mathrm{d}}$ Bologna, Bologna, ${ }^{\mathrm{e} P i s a}$, Pisa, ${ }^{\mathrm{f} G e n o a, ~ G e n o a, ~ a n d ~}{ }^{\mathrm{P}}$ Palermo, Palermo, ${ }^{\mathrm{h}}$ Regional Hospital of Bolzano, Bolzano, and \\ 'Department of Genetics, Associazione Cante of Montevecchio, Fano, Italy
}

\section{Key Words}

Short stature $\cdot \mathrm{SHOX}$ deficiency $\cdot \mathrm{GH}$ treatment $\cdot$ Madelung deformity $\cdot$ Leri-Weill dyschondrosteosis

\begin{abstract}
Background/Aims: Mutations of the short stature homeobox-containing (SHOX) gene on the pseudoautosomal region of the sex chromosomes cause short stature. GH treatment has been recently proposed to improve height in short patients with SHOX deficiency. The aim of this study was to evaluate $\mathrm{GH}$ secretion and analyze growth and safety of recombinant human $\mathrm{GH}(\mathrm{rhGH})$ therapy in short children and adolescents with SHOX deficiency. Patients and Design: We studied 16 patients (10 females; $9.7 \pm 2.9$ years old; height $-2.46 \pm 0.82$ standard deviation score, SDS) with SHOX deficiency. All subjects underwent auxological evaluations, biochemical investigations, and were treated with rhGH (0.273 \pm 0.053 mg/kg/week). Results: Impaired GH secretion was present in $37.5 \%$ of the studied subjects. Comparing baseline data with those at the last visit, we found that rhGH treatment improved growth velocity SDS (from
\end{abstract}

\section{KARGER \\ Fax +41 613061234 E-Mail karger@karger.ch} www.karger.com (c) 2012 S. Karger AG, Basel

$1663-2818 / 12 / 0000-0000 \$ 38.00 / 0$

Accessible online at:

www.karger.com/hrp
$-1.03 \pm 1.44$ to $2.77 \pm 1.95 ; p=0.001$ ), height SDS (from $-2.41 \pm 0.71$ to $-1.81 \pm 0.87 ; p<0.001)$, and IGF-1 values (from $-0.57 \pm 1.23$ to $0.63 \pm 1.63$ SDS, $p=0.010$ ) without affecting body mass index SDS. Height SDS measured at the last visit was significantly correlated with chronological age $(r=-0.618, p=0.032)$, bone age $(r=-0.582, p=0.047)$ and height SDS $(r=0.938, p<0.001)$ at the beginning of treatment. No adverse events were reported on rhGH therapy which was never discontinued. Conclusion: These data showed that impaired GH secretion is not uncommon in SHOX deficiency subjects, and that rhGH therapy may be effective in increasing height in most of these patients independent of their GH secretory status, without causing any adverse events of concern.

Copyright $\odot 2012$ S. Karger AG, Basel

\section{Introduction}

Longitudinal growth and final height are the results of multifactorial processes regulated by endocrine factors and intrinsic systems of the skeletal bones modulating

Lorenzo Iughetti, MD

Department of Pediatrics, University of Modena and Reggio Emilia

Via del Pozzo 71

IT-41124 Modena (Italy)

E-Mail iughetti.lorenzo@unimore.it 
the balance of proliferation and differentiation of chondrocytes for normal bone extension in length and width. In recent years, several studies evaluated the role of the short stature homeobox-containing (SHOX) gene on bone growth to explain some cases of growth failure associated with bone dysmorphology [1].

The SHOX gene is located on the short arms of both sex chromosomes inside the telomeric part of the pseudoautosomal region 1 (PAR1) at Xp22.3. It encodes two transcripts called SHOXa and SHOXb that are generated by alternative splicing of its $3^{\prime}$ exons. Both SHOXa and $\mathrm{SHOXb}$ are nuclear proteins acting as transcriptional factors and, probably, SHOXb transcripts act as transcriptional modulators of SHOXa [2]. The proteins seem to be specifically expressed in the growth plate in hypertrophic chondrocytes undergoing apoptosis, and they appear to play an important role in the regulation of chondrocyte differentiation and proliferation [3].

SHOX gene function is dosage dependent; therefore, the loss of function of one SHOX allele (haploinsufficiency) results in SHOX deficiency. The most frequent SHOX mutations can encompass the SHOX gene itself [4] or the regulatory enhancer regions downstream [5] or upstream of the SHOX gene [6]. These deletions account for around $80 \%$ of all mutations. Until now, 224 unique allelic variants have been reported in the SHOX database (http:// www.hd-lovd.uni-hd.de).

Haploinsufficiency of the SHOX gene was demonstrated to be causative in Leri-Weill dyschondrosteosis (LWD; OMIM 127300), a mesomelic dysplasia characterized by short stature associated with short lower legs and Madelung deformity of the forearms $[7,8]$. Turner syndrome (TS) is also associated with the loss of one SHOX gene because of the numerical or structural aberration of the $\mathrm{X}$ chromosome; so, SHOX deficiency may account for the short stature as well as some of the limb skeletal anomalies [9-11].

In many children before the age of 6 years, the characteristic signs of LWD cannot be easily detectable in spite of a careful clinical evaluation; thus, the phenotype resembles the typical presentation of idiopathic short stature (OMIM 300582), defined by a height below -2 standard deviation score (SDS) without any known specific causative disorders.

A positive response to recombinant human $\mathrm{GH}(\mathrm{rhGH})$ therapy was clearly shown in patients with TS [12], and subsequently was proposed for short stature due to isolated SHOX deficiency. However, up to now the data of only few patients treated with GH have been reported in the literature [13-15]. Moreover, there are few reports in- vestigating the frequency of altered GH secretion in subjects with SHOX deficiency.

The aim of this study was to evaluate the prevalence of impaired GH secretion in patients with genetically confirmed SHOX deficiency and the effect of rhGH on their growth.

\section{Subjects and Methods}

Clinical and Biochemical Assessment

Sixteen children and adolescents (6 males) with genetically confirmed SHOX deficiency were included in the study; they were recruited from the Pediatric Endocrinology Units of the Universities of Modena and Reggio Emilia, Turin, Bologna, Pisa, Parma, Bolzano, Genoa, and Palermo. The Ethical Committee at the coordinating center at the University of Modena and Reggio Emilia approved the study, and written informed consent was obtained from all patients' and parents for data collection at the moment of the study.

All patients underwent a complete clinical history and physical examination including anthropometric measurements that were performed by well-trained examiners according to the Anthropometric Standardization Reference Manual [16]. Height was measured to the nearest $0.1 \mathrm{~cm}$ using a wall-mounted stadiometer (Harpenden, Crymych, UK). Body weight was measured to the nearest $0.1 \mathrm{~kg}$, and body mass index (BMI) was calculated as weight in $\mathrm{kg} /$ height in meters squared and expressed as $\mathrm{z}$ score with respect to chronological age using national growth charts [17].

Pubertal development was determined using the grading system defined by Tanner for breast (B) and genital stage $(G)$ according to gender [18].

The patients were submitted to endocrinological investigations with the measurement of basal serum GH, IGF-1, IGFBP-3, $\mathrm{T}_{4}$, and TSH concentrations. Moreover, arginine $(0.5 \mathrm{~g} / \mathrm{kg}$ intravenously) and/or L-dopa (500 $\mu \mathrm{g} / 1.73 \mathrm{~m}^{2}$ orally) and/or clonidine $\left(100 \mu \mathrm{g} / \mathrm{m}^{2}\right.$, max. $150 \mu \mathrm{g}$, orally) tests were performed in different days to evaluate GH secretion. The second GH stimulation test was performed only in subjects that had a poor GH response at the first stimulation.

Altered GH secretion was defined based on the classical auxological criteria and on a poor $\mathrm{GH}$ response $(<10 \mu \mathrm{g} / \mathrm{l})$ to two stimulation tests. Considering both chronological age and pubertal stage of each single patient, priming with sex steroids before $\mathrm{GH}$ stimulation test was not considered necessary for identification of impaired GH secretion in this series.

Hormonal concentrations were determined using specific commercially available kits. GH was assayed using an IRMA assay (DIAsource ImmunoAssays SA, Louvain-la-Neuve, Belgium). The intra-assay coefficient of variation (CV) was $2.7 \%$, and the interassay $\mathrm{CV}$ was $7.2 \%$. IGF-1 was measured using an IRMA method (DSL-5600, Diagnostic System Laboratories Inc., Webster, Tex., USA). The intra-assay CV was $2.6 \%$, and the interassay $\mathrm{CV}$ was $4.4 \%$. Prior to assaying, IGFBPs were precipitated by acidethanol extraction. IGFBP-3 was measured using an IRMA method (Diagnostic System Laboratories). The intra-assay CV was $2.9 \%$ and the interassay CV $1 \%$. 
In all subjects, skeletal maturation was assessed on the basis of roentgenograms of the left hand and wrist. Bone age was determined according to the method of Greulich and Pyle [19].

\section{Molecular/Genetic Analyses for SHOX Gene Defects}

Genomic DNA was extracted from peripheral blood sample by standard methods after patients and/or parents signed an informed consent form. Genetic analysis was performed as previously described [20] and briefly summarized below.

Multi $\equiv$ ligation-dependent probe amplification (MLPA)

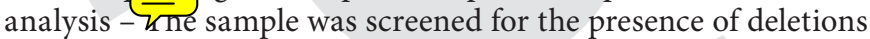
or duplications within the SHOX gene and the PAR1 region by MLPA using the SHOX salsa P018B kit (MRC-Holland, Amsterdam, The Netherlands) according to manufacturer's protocol.

Microsatellite Analysis

Microsatellite analysis was performed using the following loci: CA SHOX and DXYS10092, respectively, 15 and $3.5 \mathrm{~kb}$ upstream of SHOX, the intragenic DXS10150, DYS290 and DXYS10093, and DXS10149, DXYS233 and DXYS234, respectively $192 \mathrm{~kb}, 280 \mathrm{~kb}$ and 1.1 Mb downstream of SHOX. The microsatellites DXS10149 and DXYS233 encompass an 86-kb region including SHOX enhancer. Amplifications were performed in a reaction volume of 25 $\mu l$ containing $1 \times$ EuroTaq buffer, $1.5 \mathrm{mM} \mathrm{MgCl}_{2}, 1.25 \mathrm{U}$ EuroTaq polymerase (EuroClone, Siziano, Italy) 100 ng genomic DNA, 10 pmol fluorescently labeled forward primer, 10 pmol unlabeled reverse primer and $200 \mu \mathrm{M}$ dNTPs. Amplification products were diluted and separated by electrophoretic run on the 3100-Avant genetic analyzer automatic sequencer (Applied Biosystems, Foster City, Calif., USA). Allele sizes were determined in relation to internal size standards (Genescan 500 Rox) by use of Genescan 3.7 (Applied Biosystems).

\section{Sequence Analysis}

Point mutations and small deletions and insertions in SHOX coding sequences and intron/exon boundaries (that could account for the phenotype) were investigated by direct sequencing of all the coding exons of the gene isoform $\mathrm{A}$ (from exon 2 to exon 6a). PCR amplifications of exons were performed in $25 \mu \mathrm{l}$ reaction volume containing $1 \times$ EuroTaq buffer, $1.5 \mathrm{mM} \mathrm{MgCl}_{2}, 1.25 \mathrm{U}$ EuroTaq polymerase (EuroClone), 200 ng genomic DNA, 15 pmol of each primer and $200 \mu \mathrm{M}$ dNTPs. PCR amplicons were controlled on agarose gel, cleaned up using ExoSAP-IT (USB, Staufen, Germany) and sequenced directly in the forward and reverse directions. PCR fragments were sequenced using the same PCR amplification primers. Sequencing was performed using ABI Prism BigDye terminator V3.1 (Applied Biosystems) sequencing chemistry and isopropanol precipitation. Reactions were run on ABI 3100 capillary sequencer (Applied Biosystems) according to the manufacturer's instructions, and sequence electropherograms analyzed by Seqscape V2.0 (Applied Biosystems).

\section{GH Treatment}

All patients were submitted to rhGH treatment according to the Italian Agency for Drugs (AIFA) guidelines, at the mean dose of $0.273 \mathrm{mg} / \mathrm{kg} /$ week by daily SC injections, for at least 1 year.

Statistical Analysis

All results are presented as mean $\pm \mathrm{SD}$. The statistical analysis (STATISTICA, StatSoft Inc., Tulsa, Okla., USA) was performed using the Student's t test for paired samples, Student's t test for unpaired samples and ANOVA to locate significant differences in average values of height ( $\mathrm{cm}$ and SDS), growth velocity $(\mathrm{cm}$ and SDS), height corrected for target height SDS (TH SDS) [21], BMI $\left(\mathrm{kg} / \mathrm{m}^{2}\right.$ and SDS), bone age, and IGF-1 (ng/ml and SDS) when appropriate. Pearson's correlation was also performed to assess the presence of relationship between the variables. A p value $<0.05$ was considered significant.

\section{Results}

\section{Baseline Data}

Baseline height was $-2.46 \pm 0.82$ SDS (range from -4.30 to -1.50 SDS) and growth velocity was $-1.08 \pm 1.36$ SDS (range from -2.81 to 1.66 SDS). The TH was $-1.38 \pm$ 0.93 SDS, and children's height SDS correct for TH SDS was $-1.08 \pm 0.77$. BMI SDS was $0.16 \pm 0.97$. Bone age was $8.99 \pm 3.11$ years with a delay with respect to chronological age of $-0.76 \pm 0.87$ years. Mean IGF-1 levels were $229.8 \pm 171.9 \mathrm{ng} / \mathrm{ml}$, being below the normal range in 4 patients. IGF-1 SDS values were on average in the lownormal range $(-0.80 \pm 1.28$ SDS) despite the differences between the values of individual subjects (range from -3.01 to 1.22 SDS). The prevalence of females was $62.5 \%$ (10 out 16). No significant differences were found for height SDS and BMI SDS between males and females. Eight subjects (5 females) were prepubertal.

Details on phenotype and genotype characteristics are provided in table 1. Phenotypical findings were suggestive for LWD in 10 cases and for idiopathic short stature in 5 cases. In one case, SHOX deficiency was demonstrated in a patient who also had trichorhinophalangeal syndrome. Molecular analysis showed a mutation/deletion of the SHOX gene in all subjects. In 10 subjects, we showed minute or large deletions, while in 6 patients, we found a mutation. The same genetic alterations were demonstrated in 8 families ( 5 in fathers); in 7 families no mutations were detected, while in one family, parents did not consent to be tested for.

Thyroid function was normal in all subjects.

The first GH stimulation test showed a blunted GH response in 7 out 16 subjects, and the second stimulation test allowed us to make the diagnosis of impaired GH secretion in 6 subjects (37.5\%).

\section{Response to rhGH Treatment}

All our patients were treated with rhGH according to AIFA guidelines, but at the end of the study, 13 out 16 had completed at least 1-year follow-up $(2.31 \pm 1.59$; range 1.00-6.40). The following data, thus, are referred only to 
Table 1. Phenotype and genotype characteristics of each studied case

\begin{tabular}{|c|c|c|c|c|c|c|}
\hline Case & Gender & Age, years & Genotype & Phenotype & Height (SDS) & GH peak, ng/ml \\
\hline 1 & M & 14.5 & deletion (465C) & short stature; Madelung deformity & -3.80 & 21.0 \\
\hline 2 & $\mathrm{~F}$ & 12.0 & deletion & short stature; dyschondrosteosis & -3.00 & 21.2 \\
\hline 3 & $\mathrm{~F}$ & 5.6 & deletion & short stature & -2.40 & 28.7 \\
\hline 4 & $\mathrm{~F}$ & 11.4 & deletion & short stature & -2.20 & 17.6 \\
\hline 5 & M & 4.9 & mutation & short stature & -2.30 & 19.5 \\
\hline 6 & M & 8.5 & deletion & short stature & -2.00 & 7.49 \\
\hline 7 & $\mathrm{M}$ & 9.0 & mutation promoter & short stature; Madelung deformity & -2.10 & 6.30 \\
\hline 8 & $\mathrm{~F}$ & 8.1 & deletion & short stature; Madelung deformity & -2.02 & 12.8 \\
\hline 9 & $\mathrm{~F}$ & 6.3 & deletion & short stature & -1.68 & 7.80 \\
\hline 10 & $\mathrm{~F}$ & 11.5 & deletion & short stature; Madelung deformity & -1.80 & 7.00 \\
\hline 11 & $\mathrm{~F}$ & 10.0 & mutation & short stature; Madelung deformity & & \\
\hline & & & trichorhinophalangeal syndrome & trichorhinophalangeal syndrome & -1.50 & 7.00 \\
\hline 12 & M & 13.2 & deletion & short stature; Madelung deformity & -1.92 & 9.20 \\
\hline 13 & $\mathrm{~F}$ & 12.4 & mutation & short stature; Madelung deformity & -3.71 & 24.9 \\
\hline 14 & $\mathrm{M}$ & 10.6 & deletion & short stature; Madelung deformity & -2.10 & 13.1 \\
\hline 15 & $\mathrm{~F}$ & 6.2 & mutation & short stature; Madelung deformity & -2.60 & 11.0 \\
\hline 16 & $\mathrm{~F}$ & 11.9 & mutation & short stature; Madelung deformity & -4.30 & 37.3 \\
\hline
\end{tabular}

these subjects (table 2) excluding the 10-year-old girl with trichorhinophalangeal syndrome whose growth data will be described separately.

Growth velocity and height SDS improved in response to rhGH therapy from baseline to the last visit. In detail, rhGH treatment improved growth velocity SDS $(-1.03 \pm$ 1.44 vs. $2.77 \pm 1.95$, respectively; $\mathrm{p}<0.001)$, height SDS $(-2.41 \pm 0.71$ vs. $-1.81 \pm 0.87$, respectively; $\mathrm{p}<0.001$; fig. 1a) and height SDS correct for TH ( $-1.13 \pm 0.86$ vs. $-0.53 \pm 0.73$, respectively; $\mathrm{p}<0.001)$. The change of the height SDS of each treated subject is shown in figure $1 b$. The main significant gains in growth velocity SDS and height SDS were observed during the first year of rhGH treatment (table 2). BMI SDS was unchanged $(0.06 \pm 1.09$ vs. $0.01 \pm 0.84$, respectively; $\mathrm{p}=0.815$ ). At the last visit, the gain in height $\operatorname{SDS}(\Delta)$ was $0.60 \pm 0.32$.

A significant difference was detected between TH SDS and basal height SDS $(-1.28 \pm 0.91$ vs. $-2.41 \pm 0.71$, respectively; $\mathrm{p}=0.003$ ), while no significant difference was found with the last measured height SDS (fig. 1a).

Only the patient with SHOX deficiency and trichorhinophalangeal syndrome failed to improve height SDS on GH treatment considering that after 2.5 years of therapy her height decreased from -1.50 to -2.47 SDS (fig. $1 \mathrm{~b}$, patient 11) with a growth velocity of -4.11 SDS.

In the rhGH-treated SHOX deficiency subjects, bone age delay changed significantly from baseline to the last visit $(0.65 \pm 0.78$ vs. $0.22 \pm 0.70$ years' delay; $\mathrm{p}=0.042$; table 2), in particular in the GH deficiency (GHD) patients who had not yet entered puberty at the beginning of rhGH therapy.

IGF-1 SDS values significantly increased to the uppernormal range during rhGH treatment (from $-0.57 \pm$ 1.23 to $0.63 \pm 1.63, \mathrm{p}=0.010$ ). During rhGH treatment, IGF-1 concentrations exceeded +2 SDS at the last evaluation in 2 subjects, both with normal GH responses to stimulation tests.

\section{Correlation Analysis}

Height SDS measured during the last visit was inversely correlated with both baseline chronological age $(\mathrm{r}=$ $-0.618, \mathrm{p}=0.032$; fig. $2 \mathrm{a})$ and bone age $(\mathrm{r}=-0.582, \mathrm{p}=$ 0.047 ), while no significant correlation was found with baseline bone age delay $(r=-0.007, p=0.983$; fig. $2 b)$. Analyzing data using $\Delta$ height SDS, we found a significant correlation with bone age at baseline $(r=-0.656$, $\mathrm{p}=0.020)$ but not with chronological age $(\mathrm{r}=-0.534, \mathrm{p}=$ 0.732 ). A significant positive correlation was also found between height SDS before the beginning of the treatment and at the last visit $(\mathrm{r}=0.938, \mathrm{p}<0.001)$. The best catch-up growth was obtained in the 3 younger patients, one of whom was affected by impaired GH secretion.

Considering data after 1st-year rhGH therapy, significant correlations were only found between $\Delta$ height SDS with both baseline chronological age $(\mathrm{r}=-0.855, \mathrm{p}<$ 0.001; fig. $2 \mathrm{c})$ and bone age $(\mathrm{r}=-0.911, \mathrm{p}<0.001)$. 

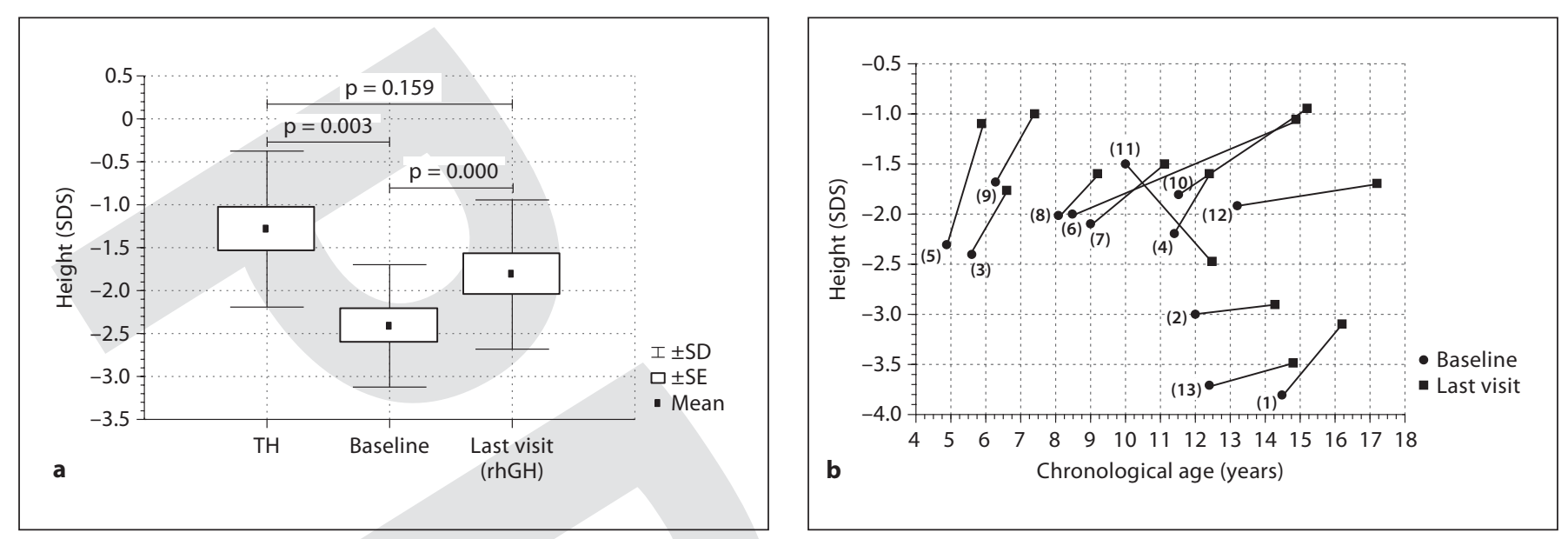

Fig. 1. a Change in height SDS during rhGH therapy in SHOX-deficient patients (Student's t test for paired samples) and differences with TH (Student's t test for unpaired samples). b Change in height SDS during rhGH therapy from baseline to end point measurement in each SHOX-deficient patient.
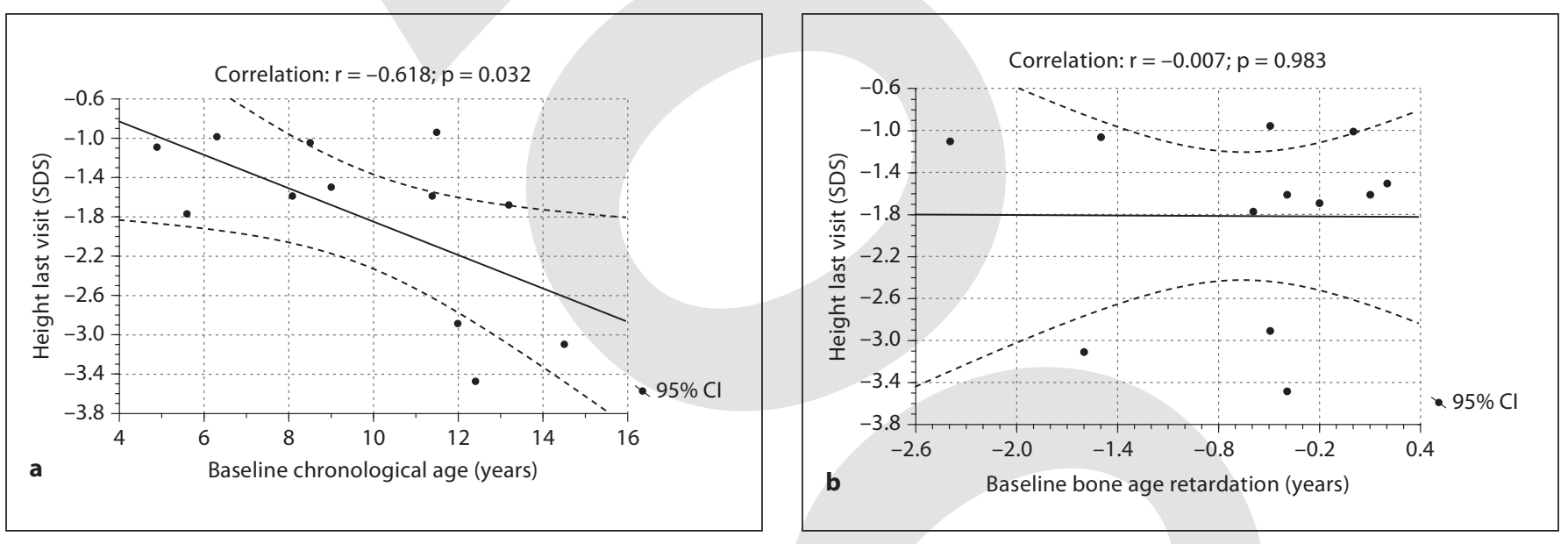

Fig. 2. Pearsons' correlations. a Last visit height SDS with baseline chronological age. $\mathbf{b}$ Last visit height SDS with baseline bone age retardation. c 1st-year height gain SDS with baseline chronological age.

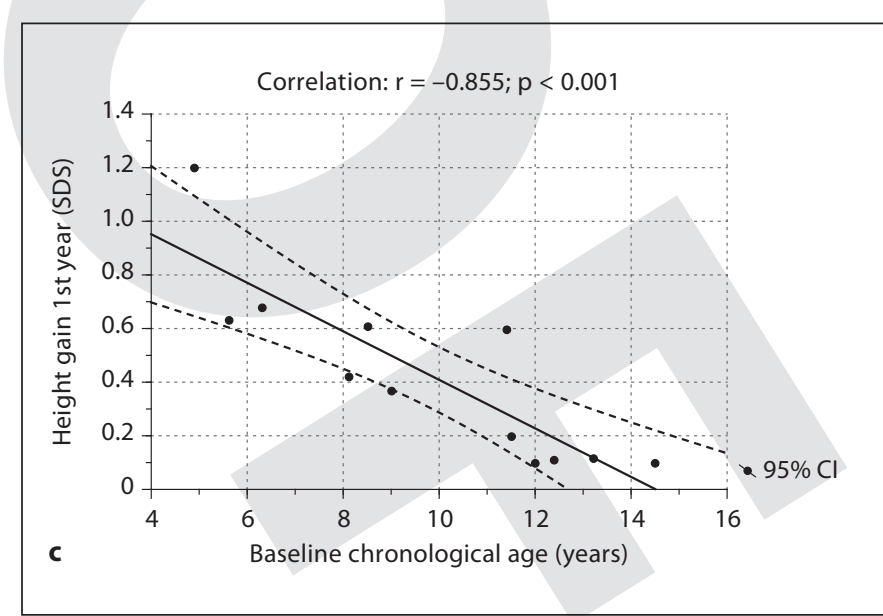

GH Therapy in SHOX-D Patients 
Table 2. Clinical and laboratory data at baseline and last visit during rhGH therapy of SHOX deficiency patients

\begin{tabular}{|c|c|c|c|c|c|c|}
\hline & \multicolumn{2}{|l|}{ All cases } & \multicolumn{2}{|l|}{ GHD } & \multicolumn{2}{|l|}{ No GHD } \\
\hline & baseline & last visit & baseline & last visit & baseline & last visit \\
\hline Chronological age, years & $9.78 \pm 3.16$ & $12.1 \pm 3.96^{*}$ & $9.70 \pm 2.69$ & $13.1 \pm 3.90^{*}$ & $9.84 \pm 3.66$ & $11.3 \pm 4.12^{*}$ \\
\hline Sex, male/female & \multicolumn{2}{|c|}{$5 / 7$} & \multicolumn{2}{|c|}{$3 / 2$} & \multicolumn{2}{|c|}{$2 / 5$} \\
\hline Puberty, yes/no & $8 / 4$ & $9 / 3$ & $4 / 1$ & $5 / 0$ & $4 / 3$ & $4 / 3$ \\
\hline Bone age, years & $8.92 \pm 3.44$ & $11.7 \pm 4.58^{*}$ & $9.30 \pm 2.77$ & $13.4 \pm 4.26^{*}$ & $9.01 \pm 3.94$ & $10.2 \pm 4.66^{*}$ \\
\hline \multicolumn{7}{|l|}{ Bone age delay, years } \\
\hline (bone age - chronological age) & $-0.65 \pm 0.78$ & $-0.22 \pm 0.70^{*}$ & $-0.40 \pm 0.67$ & $0.30 \pm 0.47$ & $-0.83 \pm 0.86$ & $-0.60 \pm 0.61$ \\
\hline Madelung deformity, yes/no & \multicolumn{2}{|c|}{$6 / 6$} & \multicolumn{2}{|c|}{$3 / 2$} & \multicolumn{2}{|c|}{$3 / 4$} \\
\hline Height, cm & $121.8 \pm 15.3$ & $136.6 \pm 19.6^{*}$ & $123.5 \pm 13.7$ & $145.1 \pm 20.3^{*}$ & $120.5 \pm 17.3$ & $130.6 \pm 18.1^{*}$ \\
\hline Height, SDS & $-2.41 \pm 0.71$ & $-1.81 \pm 0.87^{*}$ & $-1.90 \pm 0.16$ & $-1.24 \pm 0.33^{*}$ & $-2.77 \pm 0.73^{\#}$ & $-2.22 \pm 0.91^{*}$ \\
\hline $\mathrm{TH}, \mathrm{SDS}$ & \multicolumn{2}{|c|}{$-1.28 \pm 0.91$} & \multicolumn{2}{|c|}{$-1.18 \pm 0.77$} & \multicolumn{2}{|c|}{$-1.35 \pm 0.52$} \\
\hline Height, SDS correct for TH & $-1.13 \pm 0.86$ & $-0.53 \pm 0.73^{*}$ & $-0.72 \pm 0.64$ & $-0.14 \pm 0.67^{*}$ & $-1.42 \pm 0.90$ & $-0.81 \pm 0.67^{*}$ \\
\hline Final $\Delta$ height, SDS & \multicolumn{2}{|c|}{$0.60 \pm 0.32$} & \multicolumn{2}{|c|}{$0.66 \pm 0.27$} & \multicolumn{2}{|c|}{$0.55 \pm 0.36$} \\
\hline $\mathrm{BMI}_{\mathrm{L}}$ & $17.3 \pm 2.52$ & $18.2 \pm 3.22$ & $18.7 \pm 1.97$ & $18.7 \pm 1.12$ & $16.9 \pm 3.18$ & $17.9 \pm 4.04$ \\
\hline BMI, SDS & $0.06 \pm 1.09$ & $0.01 \pm 0.84$ & $0.95 \pm 0.59$ & $0.32 \pm 0.66$ & $-0.36 \pm 1.10^{\#}$ & $-0.16 \pm 0.92$ \\
\hline Growth velocity, SDS & $1.03 \pm 1.44$ & $2.77 \pm 1.95^{*}$ & $-1.72 \pm 0.64$ & $2.87 \pm 2.62^{*}$ & $-0.73 \pm 1.51$ & $3.72 \pm 1.60^{*}$ \\
\hline \multicolumn{7}{|l|}{ 1st year } \\
\hline Height, SDS & \multicolumn{2}{|c|}{$-1.98 \pm 0.91^{*}$} & \multicolumn{2}{|c|}{$-1.50 \pm 0.32^{*}$} & \multicolumn{2}{|c|}{$-2.32 \pm 1.06^{*}$} \\
\hline$\Delta$ Height, SDS & \multicolumn{2}{|c|}{$0.43 \pm 0.33$} & \multicolumn{2}{|c|}{$0.40 \pm 0.24$} & \multicolumn{2}{|c|}{$0.45 \pm 0.40$} \\
\hline Growth velocity, SDS & \multicolumn{2}{|c|}{$2.50 \pm 1.76^{*}$} & \multicolumn{2}{|c|}{$3.36 \pm 1.10^{*}$} & \multicolumn{2}{|c|}{$2.08 \pm 1.95^{*}$} \\
\hline$\Delta$ Growth velocity, SDS & \multicolumn{2}{|c|}{$3.53 \pm 2.18$} & \multicolumn{2}{|c|}{$5.08 \pm 1.50$} & \multicolumn{2}{|c|}{$2.77 \pm 2.13$} \\
\hline Max GH peak value, ng/ml & \multicolumn{2}{|c|}{$15.3 \pm 7.82$} & \multicolumn{2}{|c|}{$7.55 \pm 1.07$} & 20.8 & $\pm 5.08^{*}$ \\
\hline Median & & 5.2 & & & & 1.0 \\
\hline Q1 & & .64 & & & & 7.6 \\
\hline Q3 & & 1.1 & & & & 4.9 \\
\hline IGF-1, ng/ml & $229.0 \pm 212.8$ & $405.4 \pm 294.6^{*}$ & $162.5 \pm 90.0$ & $384.3 \pm 74.6^{*}$ & $307.1 \pm 219.6$ & $418.1 \pm 385.5$ \\
\hline IGF-1, SDS & $-0.57 \pm 1.23$ & $0.63 \pm 1.63^{*}$ & $-1.09 \pm 0.61$ & $0.74 \pm 1.35^{*}$ & $-0.37 \pm 1.35$ & $0.57 \pm 1.93$ \\
\hline rhGH, mg/kg/week & 0.27 & \pm 0.058 & 0.27 & 0.028 & 0.268 & 0.075 \\
\hline rhGH duration, years & 2.3 & \pm 1.66 & & $=1.87$ & 1.48 & 0.64 \\
\hline
\end{tabular}

${ }^{*} \mathrm{p}<0.05$, intragroup (vs. baseline); ${ }^{*} \mathrm{p}<0.05$, intergroup (vs. the same time).

\section{Subgroup Analyses}

Subjects without GHD had significantly lower baseline height SDS $(-2.77 \pm 0.73$ vs. $-1.90 \pm 0.16$ SDS, respectively; $\mathrm{p}=0.027)$ and BMI SDS with respect to the ones with impaired GH secretion $(-0.36 \pm 1.10$ vs. 0.95 \pm 0.59 SDS, respectively; $\mathrm{p}=0.036)$. Age and bone age were comparable, and no significant difference between groups was detected (table 2).

The 5 patients with impaired GH secretion and the 7 with normal GH secretion were treated with a comparable GH dosage, and showed a significant response to the rhGH. Specifically, $\Delta$ height SDS in subjects with GHD and without GHD were $0.66 \pm 0.27$ and $0.55 \pm 0.36$, respectively (NS). Moreover, patients with impaired GH production had a significant increase in IGF-1 levels that was not found in the other group (table 2).

\section{Safety}

During rhGH therapy, no discontinuation due to adverse events was found, and no adverse event of concern was reported. Moreover, Madelung deformity that was present in 6 out 12 at the start of therapy did not deteriorate during follow-up.

\section{Discussion}

Patients with mutations or deletions of the SHOX gene have variable degrees of growth impairment, with or without evident mesomelic skeletal dysplasia. Growth failure starts early during the first years of life, and the mean final height is around 2 SDS below the mean. However, longitudinal follow-up studies of children carrying 
SHOX defects suggest a relatively well-preserved prepubertal growth followed by compromised pubertal growth due to premature growth plate fusion, thus causing premature growth arrest [22]. This raises concerns regarding the adult height prognosis of these 'normal' height children with SHOX deficiency which, if untreated, generally remain short in adulthood.

An insufficient $\mathrm{GH}$ secretion was previously described in 3 subjects with SHOX mutation; however, IGF-1 and IGFBP-3 serum levels were in the normal range, so the authors concluded that classical GHD was not present in these children [13]. Subnormal GH response was also reported in 5 children with LWS [23]. Recently, Urakami et al. [24] reported that 2 sisters with SHOX deficiency had normal peak GH levels after stimulation test.

All our SHOX deficiency subjects were submitted to GH stimulation test: a blunted GH response was demonstrated in 6 out of 16 subjects. Moreover, mean IGF-1 SDS values were on average in the low-normal range. This study demonstrated that SHOX deficiency was not uncommonly associated with impaired GH secretion which was in fact detected in about $40 \%$ of our subjects.

The indication for the use of rhGH in children without classical GHD has been widened over years to diseases such as TS, chronic renal failure, being born small for gestational age and Prader-Willi syndrome. The rationale for rhGH therapy in these conditions relates to the strong dose-dependent growth-promoting effect of GH. The effect of rhGH is associated with the induction of the same intracellular signaling response triggered by endogenous $\mathrm{GH}$ and, in most cases, with increased serum concentrations of the GH-dependent peptides IGF-1 and IGFBP-3. Apart from intrinsic individual variations in responsiveness, the magnitude of the growth response to rhGH depends on other external factors, including frequency of administration, concomitant replacement of other hormones, nutritional status, age at treatment initiation, dose, and duration of treatment.

Until now, there have been reports on only about 50 subjects with SHOX deficiency treated with rhGH [25]. The first reports on the treatment of SHOX deficiency patients with rhGH did not provide a definite response on the efficacy of this treatment, showing controversial results. Two siblings with a $S H O X$ point mutation were reported to respond well to rhGH therapy $(0.33 \mathrm{mg} / \mathrm{kg} /$ week) [13]. Shanske et al. [26] and Munns et al. [27] also described a similar effect after 1 year on rhGH therapy $(0.21$ and $0.28 \mathrm{mg} / \mathrm{kg} /$ week, respectively), reporting a significant improvement in height SDS and growth velocity. These first case reports suggested that high-dose rhGH

GH Therapy in SHOX-D Patients therapy was effective in short patients with SHOX deficiency, but a recent case report showed that low-dose rhGH therapy $(0.175 \mathrm{mg} / \mathrm{kg}$ per week) was also effective in 2 young sisters [24]. In a randomized multicenter trial, subjects with genetically proven SHOX deficiency were reported to have significant growth improvement during a 2-year rhGH treatment period. Specifically, in the treated group growth velocity was $8.7 \mathrm{~cm} /$ year during the 1 st year and $7.3 \mathrm{~cm} /$ year during the 2 nd year, both significantly higher compared with growth velocity before treatment. In addition, a recent study by the same group concluded that patients with SHOX deficiency achieved comparable final height from rhGH therapy as those with TS. More recently, it was reported that 16 children treated with rhGH had an increase in height from $-2.7 \pm 0.7$ to $-1.4 \pm 0.7$ SDS. Some studied children achieved adult height $(-2.0 \pm 0.9$ SDS $)$ with a gain over baseline height of $1.0 \pm 0.5$ SDS after a mean treatment duration of 5.8 \pm 2.1 years [28]. In general, rhGH therapy is sufficiently beneficial in improving height in most cases of TS and SHOX deficiency $[14,15,29]$.

Our data confirm that growth velocity in subjects with SHOX deficiency is significantly accelerated during rhGH therapy, and suggest that treatment can result in a significant gain in height, taking $\mathrm{TH}$ also into consideration. In detail, 12 out of 13 subjects improved their growth rate on rhGH treatment, and this resulted in a progressive increase in height SDS; only the patient with SHOX deficiency and trichorhinophalangeal syndrome failed to improve height SDS during hormonal treatment.

Moreover, one must consider that the lack of a significant difference between the children's heights and THs at the last visit could be ascribed also to the effect of their genetic background (short parents having SHOX deficiency). This represents a limit of the study which, however, cannot be overcome.

The SHOX deficiency patients with normal GH secretion showed the same response to rhGH treatment as those with impaired GH secretion. However, as a bias of our study, we must point out that because of the different duration of rhGH treatment between subjects with impaired and normal GH secretion, growth response variables at the last visit cannot be directly compared. Interestingly, in the subjects with impaired GH secretion, baseline height SDS was higher than in those with normal GH secretion. This finding could be partially explained by the early identification of altered GH secretion and subsequently of SHOX deficiency according to the knowledge developed during recent years which forced us to 
include SHOX gene analysis in the workup of short patients without impaired GH secretion.

Treatment response was similar between males and females. With respect to previous published studies, the lower gain in height SDS we found in our SHOX-deficient patients may reflect a delay in starting rhGH treatment (mean age 9.8 years) and the low mean rhGH dose $(0.27$ $\mathrm{mg} / \mathrm{kg} /$ week) used.

It is well known that prepubertal height is an important predictor of adult height, and Davenport et al. [30] demonstrated that starting rhGH early in children with TS not only prevented further worsening of height SDS but normalized height after 2 years of treatment. Our study supported, at least in part, these data considering that height SDS measured at the last visit was inversely correlated with both baseline chronological age and bone age; moreover, a significant positive correlation was found with height SDS before the beginning of the treatment. Furthermore, the best catch-up growth was obtained in the 3 younger patients, independent of GHD.

The mechanism by which SHOX regulates linear growth and why its deficiency results in short stature is not completely understood. In vitro experiments suggest an antiproliferative effect of SHOX [1,3].

Based on the evidence that rhGH treatment induced catch-up growth in short patients with SHOX deficiency [14] and resulted in gain in final height SDS, which would probably not be attained spontaneously, the height gain in these treated patients could be likely due to a direct treatment effect of rhGH. Considering the relatively low baseline IGF-1 concentrations in our subjects, one could also speculate that SHOX may be involved in the regulation of the IGF-1 gene. Furthermore, IGF-1 levels responded well to rhGH therapy, supporting further the hypothesis that there is no evidence of $\mathrm{GH}$ resistance or insensitivity [14].

Subjects with SHOX deficiency generally undergo normal pubertal development with appropriate bone age progression. We cannot discuss the contribution of estro- gen/testosterone to skeletal maturation. Studies in children with SHOX deficiency demonstrated a near-normal prepubertal growth rate, with a more affected pubertal growth due to premature growth plate fusion suggesting important effects of gonadal hormones (especially estrogens in females) [20,29]. Ogata et al. [31] have shown that $\mathrm{GnRH}$ analog therapy associated with rhGH treatment before entry into puberty might be useful to prevent the development of skeletal lesions, and could help in the improvement of final height, especially in female patients with SHOX deficiency. More recently, Scalco et al. [22] compared, in a small group of children with SHOX deficiency, the adult height of a control group with the adult height of a group who used the combination of rhGH and GnRH analog with the aim of delaying the fusion of the growth plates. They showed that the control group had a height of -1.2 SDS at the beginning of puberty and an adult height of -2.5 SDS, whereas children in the treatment group improved their height from -2.3 SDS at the beginning of puberty to an adult height of -1.7 SDS. It was not clear, however, whether rhGH alone or the combination of rhGH with GnRH analog increased further adult height.

There was no evidence of any new or unexpected rhGH-related adverse events in the SHOX deficiency patient population in which this hormonal treatment showed a safety profile comparable to that reported in other pediatric indications for which rhGH has previously been approved [32, 33].

In conclusion, our data showed that in SHOX deficiency subjects an altered GH secretion is not uncommon, and rhGH therapy may be effective in increasing height in most of these patients independent of GH secretion, without causing adverse events of concern.

\section{Disclosure Statement}

Nothing to declare.

\section{References}

1 Binder G: Short stature due to SHOX deficiency: genotype, phenotype, and therapy. Horm Res Paediatr 2011;75:81-89.

2 Rao E, Blaschke RJ, Marchini A, Niesler B, Burnett M, Rappold GA: The Leri-Weill and Turner syndrome homeobox gene SHOX encodes a cell-type specific transcriptional activator. Hum Mol Genet 2001;10:3083-3091.
3 Marchini A, Marttila T, Winter A, Caldeira S, Malanchi I, Blaschke RJ, Häcker B, Rao E, Karperien M, Wit JM, Richter W, Tommasino M, Rappold GA: The short stature homeodomain protein SHOX induces cellular growth arrest and apoptosis and is expressed in human growth plate chondrocytes. J Biol Chem 2004;279:37103-37114.
4 Schiller S, Spranger S, Schechinger B, Fukami M, Merker S, Drop SL, Tröger J, Knoblauch H, Kunze J, Seidel J, Rappold GA: Phenotypic variation and genetic heterogeneity in Léri-Weill syndrome. Eur J Hum Genet 2000;8:54-62. 
5 Chen J, Wildhardt G, Zhong Z, Röth R, Weiss B, Steinberger D, Decker J, Blum WF, Rappold G: Enhancer deletions of the SHOX gene as a frequent cause of short stature: the essential role of a $250 \mathrm{~kb}$ downstream regulatory domain. J Med Genet 2009;46:834-839.

6 Benito-Sanz S, Aza-Carmona M, RodríguezEstevez A, Rica-Etxebarria I, Gracia R, Campos-Barros A, Heath KE: Identification of the first PAR1 deletion encompassing upstream SHOX enhancers in a family with idiopathic short stature. Eur J Hum Genet 2012;20:125-127.

7 Shears DJ, Vassal HJ, Goodman FR, Palmer RW, Reardon W, Superti-Furga A, Scambler PJ, Winter RM: Mutation and deletion of the pseudoautosomal gene SHOX cause LeriWeill dyschondrosteosis. Nat Genet 1998;19: 70-73.

8 Cormier-Daire V, Belin V, Cusin V, Viot G, Girlich D, Toutain A, Moncla A, Vekemans M, Le Merrer M, Munnich A: SHOX gene mutations and deletions in dyschondrosteosis or Leri-Weill syndrome. Acta Paediatr 1999;88:55-59.

9 Ellison JW, Wardak Z, Young MF, Gehron Robey P, Laig-Webster M, Chiong W: PHOG, a candidate gene for involvement in the short stature of Turner syndrome. Hum Mol Genet 1997;6:1341-1347.

10 Rao E, Weiss B, Fukami M, Rump A, Niesler B, Mertz A, Muroya K, Binder G, Kirsch S, Winkelmann M, Nordsiek G, Heinrich U, Breuning $\mathrm{MH}$, Ranke MB, Rosenthal A, Ogata T, Rappold GA: Pseudoautosomal deletions encompassing a novel homeobox gene cause growth failure in idiopathic short stature and Turner syndrome. Nat Genet 1997;16:54-63.

11 Kosho T, Muroya K, Nagai T, Fujimoto M, Yokoya S, Sakamoto H, Hirano T, Terasaki H, Ohashi H, Nishimura G, Sato S, Matsuo $\mathrm{N}$, Ogata T: Skeletal features and growth patterns in 14 patients with haploinsufficiency of SHOX: implications for the development of Turner syndrome. J Clin Endocrinol Metab 1999;84:4613-4621.

12 Stephure DK, Canadian Growth Hormone Advisory Committee: Impact of growth hormone supplementation on adult height in turner syndrome: results of the Canadian randomized controlled trial. J Clin Endocrinol Metab 2005;90:3360-3366.

13 Binder G, Schwarze CP, Ranke MB: Identification of short stature caused by SHOX defects and therapeutic effect of recombinant human growth hormone. J Clin Endocrinol Metab 2000;85:245-249.
14 Blum WF, Crowe BJ, Quigley CA, Jung H, Cao D, Ross JL, Braun L, Rappold G: SHOX Study Group. Growth hormone is effective in treatment of short stature associated with short stature homeobox-containing gene deficiency: two-year results of a randomized, controlled, multicenter trial. J Clin Endocrinol Metab 2007;92:219-228.

15 Blum WF, Cao D, Hesse V, Fricke-Otto S, Ross JL, Jones C, Quigley CA, Binder G: Height gains in response to growth hormone treatment to final height are similar in patients with SHOX deficiency and Turner syndrome. Horm Res 2009;71:167-172.

16 Lohman TG, Roche AF, Martorell R: Anthropometric Standardization Reference manual. Human Champaign, Human Kinetics Books, 1988.

17 Cacciari E, Milani S, Balsamo A, Spada E, Bona G, Cavallo L, Cerutti F, Gargantini L, Greggio N, Tonini G, Cicognani A: Italian cross-sectional growth charts for height, weight and BMI (2 to 20 years). J Endocrinol Invest 2006;29:581-593.

18 Marshall WA, Tanner JM: Variations in pattern of pubertal changes in girls. Arch Dis Child 1969;44:291-303.

19 Greulich WW, Pyle SI: Radiographic Atlas of Skeletal Development of the Hand and Wrist, ed 2. Stanford, Stanford University Press, 1959.

20 Iughetti L, Capone L, Elsedfy H, Bertorelli R, Predieri B, Bruzzi P, Forabosco A, El Kholy M: Unexpected phenotype in a boy with trisomy of the SHOX gene. J Pediatr Endocrinol Metab 2010;23:159-169.

21 Tanner JM, Goldstein H, Whitehouse RH: Standards for children's height at ages 2-9 years allowing for heights of parents. Arch Dis Child 1970;45:755-762.

22 Scalco RC, Melo SS, Pugliese-Pires PN, Funari MF, Nishi MY, Arnhold IJ, Mendonca $\mathrm{BB}$, Jorge AA: Effectiveness of the combined recombinant human growth hormone and gonadotropin-releasing hormone analog therapy in pubertal patients with short stature due to SHOX deficiency. J Clin Endocrinol Metab 2010;95:328-332.

23 Thuestad IJ, Ivarsson SA, Nilsson KO, Wattsgård C: Growth hormone treatment in Léri-Weill syndrome. J Pediatr Endocrinol Metab 1996;9:201-204.
24 Urakami T, Hasegawa M, Morimoto S, Saitoh H, Mugishima H: Effect of growth hormone therapy in two sisters with SHOX haploinsufficiency. Pediatr Int 2009;51:574599.

25 Iughetti L, Madeo S, Predieri B: Growth hormone therapy in patients with short stature homebox-gene (SHOX) deficiency. J Endocrinol Invest 2010;33:34-38.

26 Shanske A, Ellison J, Vuguin P, Dowling P, Wasserman E, Heinrich J, Saenger P: Deletion of the pseudoautosomal region in a male with a unique $\mathrm{Y} ; 13$ translocation and short stature. Am J Med Genet 1999;82:34-39.

27 Munns CF, Berry M, Vickers D, Rappold GA, Hyland VJ, Glass IA, Batch JA: Effect of 24 months of recombinant growth hormone on height and body proportions in SHOX haploinsufficiency. J Pediatr Endocrinol Metab 2003;16:997-1004

28 Salmon-Musial AS, Rosilio M, David M, Huber C, Pichot E, Cormier-Daire V, Nicolino M: Clinical and radiological characteristics of 22 children with SHOX anomalies and familial short stature suggestive of Léri-Weill dyschondrosteosis. Horm Res Paediatr 2011; 76:178-185.

29 Jorge AA, Funari MF, Nishi MY, Mendonca BB: Short stature caused by isolated SHOX gene haploinsufficiency: update on the diagnosis and treatment. Pediatr Endocrinol Rev 2010;8:79-85.

30 Davenport ML, Crowe BJ, Travers SH, Rubin K, Ross JL, Fechner PY, Gunther DF, Liu C, Geffner ME, Thrailkill K, Huseman C, Zagar AJ, Quigley CA: Growth hormone treatment of early growth failure in toddlers with Turner syndrome: a randomized, controlled, multicenter trial. J Clin Endocrinol Metab 2007;92:3406-3416.

31 Ogata T, Matsuo N, Nishimura G: SHOX haploinsufficiency and overdosage: impact of gonadal function status. J Med Genet 2001;38:1-6.

32 GH Research Society: Critical evaluation of the safety of recombinant human growth hormone administration: statement from the Growth Hormone Research Society. J Clin Endocrinol Metab 2001;86:1868-1870.

33 Quigley CA, Gill AM, Crowe BJ, Robling K, Chipman JJ, Rose SR, Ross JL, Cassorla FG, Wolka AM, Wit JM, Rekers-Mombarg LT, Cutler GB Jr: Safety of growth hormone treatment in pediatric patients with idiopathic short stature. JClin Endocrinol Metab 2005;90:5188-5196. 